\title{
The Quest for Bilingual Chinese Poetry: Poetic Tradition and Modernity
}

\begin{abstract}
Chinese poetic tradition presents such a self-centred system that it seems almost impossible to imagine a bilingual poet working with two languages, one of which is Chinese. It is highly significant to explore what changes in this situation (if any) one can observe in the realm of contemporary Chinese poetry with its openness to foreign influences and important shifts in the poet's persona. The first part of this exploration is an analysis of poets' critical and theoretical writing that elaborates themes of poetic language and cultural identity. These are further examined with the help of a series of interviews with poets representing different faces of multiethnic Chinese society. The result shows discrepancies between the projected identity of a globalized "Chinese poet" and the vision of a bilingual poet as one rooted in the culture of minorities. The second part is dedicated to a case study of the Australian-Chinese poet Ouyang $\mathrm{Yu}$, who represents a unique case of Chinese-English bilingualism. Ouyang Yu uses several strategies for constructing his multicultural identity, maintaining an illusion that it is the reader and not the author who is an alien in need of the poet to guide him through an unfamiliar linguistic landscape.
\end{abstract}

Keywords: bilingualism, Chinese literature, Chinese poetry, Ouyang Yu

\section{Bilingualism and Chineseness: Sensing the tension}

When it comes to bilingualism in contemporary Chinese poetry, the researcher faces a difficult situation. ${ }^{1}$ Chinese poetic tradition presents such an enclosed, self-centred system that it seems almost impossible to imagine a bilingual poet working simultaneously with two languages - one being Chinese, and the other standing for an alternative cultural pool. It is highly significant to explore what

\footnotetext{
1 A Russian Science Foundation (RSF) grant (19-18-00429) from the Institute of Linguistics, Russian Academy of Sciences made this research possible. The first version of this paper was presented at the ICLA 2016 Conference in Vienna. The author would like to thank the conference's diverse audience for their feedback. The author is also grateful for the research support provided by the RHF.
}

Ә Open Access. ( 2020 Yulia Dreyzis, published by De Gruyter. (ल) BY-NC-ND This work is licensed under a Creative Commons Attribution-NonCommercial-NoDerivatives 4.0 License. 
changes (if any) in this situation we can observe in the realm of contemporary Chinese poetry with its apparent openness to foreign influences and the crucial shifts in the poet's persona.

Chineseness is a much-problematized notion in modern Chinese poetry (Lee 2015, 160). With its close ties to the classical poetic tradition, modern poetry has always been burdened with a presumed loss of authenticity (Yeh 2008, 13). Rey Chow observes that this kind of "habitual obsession with "Chineseness"' might be a symptom of a "historically conditioned paranoid reaction to the West" (Chow 2000 , 5). This reaction is an effect of past victimization that turns into a "megalomanic affirmation of China" (Chow 2000, 5). The stunning result is a negative definition of Chineseness: to be Chinese means above all things to be non-Western. Chinese literary criticism only further supports and strengthens the notion of an acute need to legitimate Chinese cultural identity.

A recent debate between so-called intellectual (知识分子 zhishifenzi) and popular (or 民间 minjian) poets ${ }^{2}$ also focuses on the question of whether Chinese authors should imitate their Western "masters" or write poems which are based on the quotidian, using native inspiration as their source. Such poetic nationalism drove a major poet from the border province of Yunnan, Yu Jian 于坚, to state: “I don't believe any Chinese poets can write in other languages," and "for Chinese poets, English is an infinitely second-rate language." 3

The intellectuals attracted criticism for using "Western resources" - extensively quoting from J. L. Borges, J. Derrida, T. S. Eliot, M. Foucault, B. Pasternak, W. B. Yeats, and others in almost every line. Minjian authors, in turn, have provoked a fire of criticism for their tendency to secularize poetry, to please the taste of the masses with a particular attention to the shameful details of everyday life. These two groups have been fighting for influence and the right to dominate the Chinese poetry scene since the turn of the century. The struggle reached its peak in April 1999, during the so-called Panfeng debate 盘峰论战 (named after a hotel in Beijing where a poetry conference took place). The subsequent confrontation lasted for several months and ended only with the Longquan Poetry Conference 龙泉诗会 in Changping on 12-13 November of the same year, which the intellectuals boycotted.

2 An extensive description of the popular-intellectual polemic can be found both in Van Crevel (2008, 399-459) and in Li Dian's article on poetic debate in contemporary China (Li 2008), so it seems unnecessary to provide it here. I will dwell only on the issues that are bound up with the perception of poetic language, sticking to Li Dian's usage of the term minjian as one that definitely lacks an equivalent English term.

3 As quoted in an insightful article by Ouyang Yu (2007). 
While the intellectuals and the minjian-oriented poets have a shared vision of poetic verse as a "sublimation" of the ordinary, in practice they are increasingly aware that poetic language is itself a kind of deviation. It is a parade of abnormalities, even as it aspires to let the ordinary rule. And therein lies the paradox of contemporary Chinese verse: Chinese authors see themselves both as continuators of Chinese aesthetical and philosophical traditions as well as heirs of Western philosophy and Western modernism's linguistic experimentation. They borrow traditional techniques to create connections with classical images and the tradition of twentieth-century Chinese New Poetry. ${ }^{4}$

\section{Bilingualism and authenticity: The projected identity}

Despite the discrepancies between the two groups, both show great concern over the problem of Chineseness, or rather, what constitutes it in the contemporary poetry of China. We can see this from an analysis of critical and theoretical writing in which poets elaborate themes of poetic language and cultural identity. It is also visible in a series of forty-two interviews with contemporary Chinese poets representing different faces of multi-ethnic Chinese society, each coming from a different locality and possessing a distinct individual background. These interviews were conducted by the present author in 2015-2017, translated into Russian, and later partly published on the Russian-language blog VerseVagrant, which is devoted to contemporary Chinese poetry (www.versevagrant.com). ${ }^{5}$ Among other

4 This term was coined during the May Fourth (1919) era to designate modern Chinese poetry that uses vernacular written Chinese instead of the classical language. The formal revolution in Chinese poetry was largely a language revolution, and even then only a revolution in some particular aspects of poetry, such as prosody and content.

5 The poets interviewed are An Qi 安琪(b.1969), Bai Hua 柏桦(b. 1956), Che Qianzi 车前子(b. 1963), Chen Dongdong 陈东东 (b. 1961), Chun Sue 春树 (b. 1983), Han Bo 韩博 (b. 1973), Han Dong 韩东 (b. 1961), He Xiaozhu 何小竹 (b. 1963), Lanlan 蓝蓝 (b. 1967), Li Heng 黎衡 (b. 1986), Li Suo 里所 (b. 1986), Li Yawei 李亚伟 (b. 1963), Liu Waitong 廖伟棠 (b. 1975), Lü De’an 吕德安 (b. 1960), Lü Yue 吕约 (b. 1972), Ming Di 明迪 (b. 1963), Sang Ke 桑克 (b. 1967), Shen Haobo 沈浩波 (b. 1976), Sun Wenbo 孙文波 (b. 1959), Tu’ao 凸凹 (b. 1962), Wang Dongdong 王东东 (b. 1983), Wang Jiaxin 王家新 (b. 1957), Wang Xiaoni 王小妮 (b. 1955), Wu Ang 巫昂 (b. 1974), Wuqing 乌青 (b. 1978), Xi Du 西渡 (b. 1967), Xiao Kaiyu 萧开愚 (b. 1960), Xiao Shui 肖水 (b. 1980), Xuanyuan Shike 轩辕轼轫 (b. 1971), Yan Li 严力 (b. 1954), Yang Li 杨黎 (b. 1962), Yang Lian 杨炼 (b. 1955), Yang Xiaobin 杨小滨 (b. 1963), Yi Sha 伊沙 (b. 1966), Yu Jian 于坚 (b. 1954), Yu Youyou 余幼幼 (b. 1990), Zhai Yongming 翟 
questions, the poets were asked to answer how they perceive the future of dialectal poetry and how they assess bilingual writing rooted in Chinese.

What strikes one most are the discrepancies between the projected ideal identity of a globalized "Chinese poet" and the vision of a bilingual Chinese poet as one rooted in the culture of ethnic minorities. Most authors did not fail to mention how they have been influenced - in one way or another - by Western poetic tradition, including French symbolism (C. Baudelaire, A. Rimbaud, P. Valéry), English and American poetry of the twentieth century (W. H. Auden, E. E. Cummings, T. S. Eliot, R. Frost, A. Ginsberg, S. Plath, E. Pound), A. Pushkin, M. Lermontov, M. Tsvetaeva, A. Akhmatova, I. Brodsky, P. Celan, C. Miłosz, and many others. Many are also active as translators of poetry. Among them, Wang Jiaxin states that "we may well include foreign-language elements in our work, to bring some newness, otherness, tension to the Chinese language; that is exactly how Chinese New Poetry has always developed" (Wang 2016; my translation). He admits that this is also an impetus for his translations.

When it comes to discussing bilingual writing, poets readily perceive it as being marginal. The language that they are so actively talking about turns out to be mostly the Chinese language. This is interesting to trace in the minjian camp, where a particular stress - at least declaratively - is laid on dialectal language components, while the colloquial is often substituted by dialect and slang.

As the poet Tu'ao proclaims when he faces the question of whether bilingualism exists at all in contemporary China, "poets belonging to ethnic minorities write in Chinese and their native language" (Tu'ao 2015; my translation). Bilingualism in contemporary Chinese poetry, despite poets' much greater openness to other cultures, seems available primarily within a frame of interaction with "peripheral" literature - be it the language of "small nations" (Tibetan, Miao, and so on) or a topolect (Min, Hakka, and so on). ${ }^{6}$ Bilingual poets of Taiwan, who wrote in both Japanese and Chinese, mainly in the period of Japanese colonial administration (1895-1945), might present a special case, but they seem to fall out of the big picture entirely, going practically unmentioned by contemporary authors from mainland China. This situation is deeply rooted in the role of literary criticism (and metapoetic writing) in China as a tool for working out a "troubled relationship to the West" (Liu 1995, 184). As Lee Tong-King remarks, the act of legitimating Chineseness through literary criticism continues through the present age

永明 (b. 1955), Zhang Zhihao 张执浩 (b. 1965), Zheng Xiaoqiong 郑晓琼 (b. 1980), Zhou Lunyou 周伦 佑 (b. 1952), Zhou Yaping 周亚平 (b. 1955), and Zhu Zhu 朱朱 (b. 1969).

6 Here, I use Victor Mair's terminology $(1991,7)$. Mair believed that the term "topolect” was the most accurate and neutral translation for the Chinese term fangyan 方言. 
as China and Chineseness "become sites of tension in their encounter with cultural globalization” (Lee 2015, 164).

\section{Bilingualism and multiculturalism: The case of Ouyang Yu}

It is all the more interesting to consider bilingualism in a poet whose work brings together two significant traditions of verse, one of which is truly independent from China. Is such a model ever possible? What strategies should it use? We turn here to the unique case of the Australian-Chinese poet Ouyang $\mathrm{Yu}$, who represents "large-scale" bilingualism where both languages in use are carriers of genuinely independent poetic traditions. To date, he is the author of seventy-three books of poetry, prose, essays, translations, and literary criticism in both English and Chinese. Since 1996, he has also edited Australia's only Chinese literary magazine, Otherland 原乡 (Ouyang 2010a). From 2004 to 2013, Ouyang Yu's poems were included nine times in the collections of Best Australian Poetry. His latest collection of Chinese-language verse (Poem Not Poem 诗非诗) was published in Shanghai in 2011, and a bilingual edition of Self Translation appeared in August 2012.

Ouyang Yu was born in 1955 in the Chinese city of Huangzhou, Hubei. In 1983, he graduated from the Wuhan Institute of Hydrotechnics (now part of Wuhan University), becoming a bachelor in English and American literature, and in 1989 he received a master's degree in Australian and American literature from the East China Normal University in Shanghai. After a brief teaching period in Wuhan, he went to Australia in 1991 to obtain his $\mathrm{PhD}$ for a thesis on the image of the Chinese in Australian literature. After arriving in Australia, Ouyang Yu began his literary career as a poet, critic, translator, editor, and writer. He received grants and awards for his work, and held the position of research assistant at various Australian universities. From 2005 to 2008, he was also a professor of Australian literature at Wuhan University in China. Ouyang Yu joined the list of hundred most influential Melbourne residents in 2011, and made it into the top ten of the most influential writers of the Chinese diaspora (Tranter and Webby 2004).

Ouyang $\mathrm{Yu}$ is a highly controversial figure in Australian literature, where he is sometimes described as "the angry Chinese poet" (Ommundsen 1998). In his oft-quoted work "An Identity CV" (2004), the poet describes himself as "Australian for the last couple of years, Chinese for the first 43; unashamed of either" (Ouyang 2004a). Ouyang Yu cultivates an image of the Other that becomes at times unconvincing due to his own cultural and temporal distance from pre-mul- 
ticultural Australia. In this respect, the poems accumulated in Self Translation present a stark contrast - by creating texts in Ouyang Yu's native language (and out of it), the collection allows marginal identity to dissolve, dismissing the minority tag.

In line with Ouyang Yu's confrontational strategy, his linguistic clumsiness seems intentional: English presumably is not native to the lyric subject, and it is assumed that the subject exists in a polemically defined relationship with his non-migrant addressee. The reader is encouraged to abandon restrictive cultural standards like outdated immigration policies. The same deliberate approach is present in "Song for an Exile in Australia” 流放者的歌 (1993; Ouyang 2013, 1721), where the author deliberately uses the agrammatical "disconnected with life" and "every face of clocks" instead of the correct "disconnected from life" and "every clock face." The collection retains this poem in its original version. By opting not to date any poems in the collection and not to mark their chronological order, Ouyang Yu includes fragments of this seemingly overcome clumsiness in his poetic diary of a "season without languages in Australia."

Another poem, “Beautiful Death” 美丽的死 (2003; Ouyang 2013, 82-83), contains several options for transposing words in the sentence "The death of nature is most beautiful." The lyric subject almost rolls foreign words in the mouth of his perception, repeating the original phrase many times. Strangest of all from the linguistic point of view is the middle stanza, where the subject and predicate are not consistent with each other in number, and the author plays with the Australian meaning of the word mob, "herd."

This awkward freedom of Ouyang Yu's approach, where any violation of linguistic norms serves more as a stylistic constant, is consistent with the experience which he describes as a kind of "rootlessness" (quoted in Nicholl 2013, 1). In the poem “My Two Women” 我的兩個女人 (2002) he writes:

\author{
從前的女人姓華 \\ 如今的女人姓澳 \\ 若為自由之故 \\ 二者皆可抛 \\ [...] \\ My previous woman was called hua \\ And my current woman was called ao \\ For the sake of freedom \\ Both can be abandoned. ${ }^{7}$ (Ouyang 2013, 172-174)
}

7 Hua means "China” and ao means "Australia." 
Explicit social themes are largely absent from the introspective lyrics of Self Translation, but this does not mean that they do not appear somewhere in the background. In contrast to the dramatized polylogues of the previous years, in this collection Ouyang Yu speaks "in his own voice." If these poems are to be placed on the scale of self-reflection, with figurative description on the left and a metaphysical argument on the right, they will be located in the middle, with a slight shift to the left, for they are a combination of vivid imagery and lyrical affect.

The reverse side of this exceptional ability to construct an image is the ability to provoke. Ouyang Yu's poem “Untitled/Because That's the Way It Is” (1995) is deprived of a title because, as a Chinese Australian, or an Australian Chinese, he (and the reader of the poem) is caught in a gap between cultures, between languages, and thus rendered nameless.

The poetry of Ouyang Yu refuses to let anyone in - it instead maintains its central core or essential meaning in secret. This does not mean that it is intentionally obscure: at a superficial level, it is quite simple (often prosodical), not only in terms of spatial organization and construction, but also in terms of sound and tone. This provides a constant emotional tension that makes it difficult for the reader to find a way to enter its world:

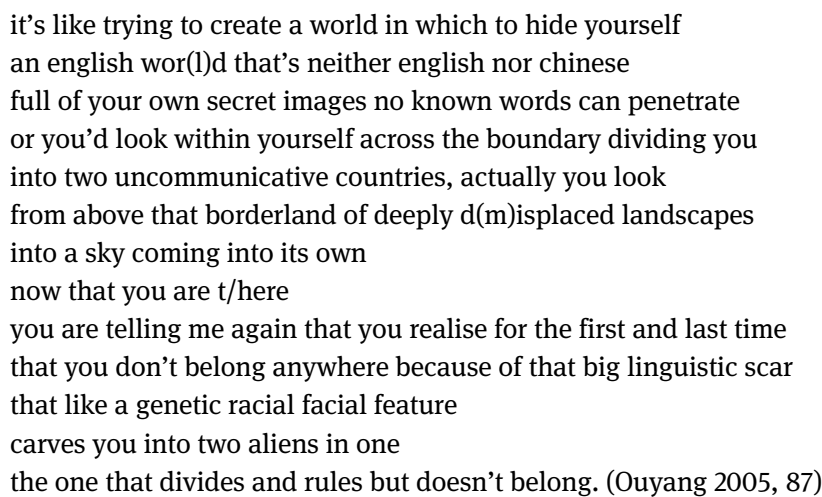

For Ouyang $\mathrm{Yu}$, poetry is a language corpus which is capable of grasping an individual "I" only briefly. Poetry presents a set of frames in the constant process of translating one's identity - a process especially important for a migrant but which constitutes, in fact, an integral part of any human experience. Ouyang Yu speaks about his deep connectedness and disunity with the land and language:

in a season without languages in Australia

I have lost my weight in undeveloped no-person's land

like a wild devil roaming 
I sow my language into the alien soil where it sends forth strange flowers that no one recognises and all of a sudden I find my tongue held between two languages like a vice in a season of self-exile in Australia (Ouyang 2013, 21)

The "o" that falls out of the word "voice" to turn it into "vice" is a gap, a hole through which the voice is lost. The lyric subject is deprived of means by which he can formulate and provide a meaningful identity - the value of his "I," which is created in the community, that is, the structure or the intimate space of a study of what is happening in psychological and poetic terms when a person is ungrounded, displaced. In the course of this study, the reader of/listener to Ouyang Yu's poetry necessarily comes to partake in the translation process. He is invited to participate in the language game again and again:

Di皮lation

Take it to heights, further 烸s

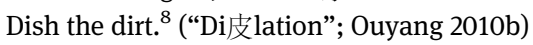

And:

my name is

a crystallization of two cultures

my surname is china

my given name is australia

if $i$ translate that direct into english

my surname becomes Australia

my given name china

[...]

wherever i go

it is with a heart tinged in two colours

although there is a han jian in chinese

there isn't ao jian in english

i write in chinese

like australians do in english

our motherlands have one thing in common

they've both lost M

i have nullified my home

$i$ have set up a home

in two hundred years' time

i shall be the father of the double man..$^{9}$ ("The Double Man," 2012; Ouyang 2013, 41)

8 The first Chinese character is pronounced as "pi" and the second as "hai."

9 Han jian is the general Chinese word for "traitor," which literally means "traitor of China." Ao stands for Australia. 
A final example is “At Dusk" (2012; Ouyang 2013, 65-66), which could also be read in the order of lines 1324 / 5768 / 9111012.

These examples demonstrate how creative play enters Ouyang Yu's texts by

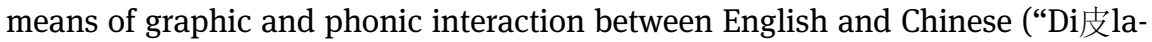
tion"), metatextual guidelines to help the reader interpret the text ("At Dusk"), and the extensive use of puns, word-game techniques, and Chinese-English synthetic units. The mixing of two languages within the space of one poem, up to their mixing within one language unit, is complemented by a wide layer of language interaction "on the borderland" between two languages, where units of another language are introduced that will be perceived as alien, often incomprehensible signs that need to be explained by the poet. Thus, the presumed reader's and poet's identities become shifted: the immigrant subject of the poem who exemplifies the Other makes the reader feel alien on the familiar ground of his own language, thus posing the question of whether a language can be owned and mastered.

Self Translation ends with three spectacular visual poems that combine two languages - Chinese and English. The first one, “双/Double,” consistently translates each line of the poem; here the poet plays thematically on alternation, including alternating spaces of black and white as presented on the page (Ouyang 2013, 235). The last poem in the collection, “Two Roads” 两条路, returns the reader to the bilingual format, but now both pages include Chinese and English, which alternate not only line by line but also within a single unit. This creates two paired poems - a meditation on Robert Frost's "The Road Not Taken" which encourages the monolingual reader to take both ways (poems) by reading Chinese or English words, jumping from left to right and back (Farrell 2013). The last strophe in both poems is in both languages, with the word "taken" removed from the English text and replaced by its Chinese equivalent, which appears in Chinese text on the left-hand page. The poem ends with an extra line in English on the left-hand page, which is occupied by mostly Chinese verse: "There is nothing that you can not do what you are doing." On the opposite page, the strophe ends with "You have no choice, you have many choices." It corresponds to an empty space on the left, which embodies potency, the future of not-yet-implemented translation. This sums up the endless ambiguity disguised as simplicity that characterizes the individual style of Ouyang Yu. Like Robert Frost's traveller and some characters of Jorge Luis Borges, Ouyang Yu and his self-translation face steadily divergent paths. The difference lies in the fact that they are unable not to follow both - simultaneously.

In his detailed exploration of the trope of translation in Chinese experimental literature, Lee Tong-King offers other examples of writing that exploits the multimodality of meanings created by the "self-translation" experiment (the most radi- 
cal being that of the Taiwanese poet Hsia Yü 夏宇 [b. 1956]). However, Hsia presents an unlikely frame of reference for exploring Chinese bilingual poetry, despite the fact that her Chinese and English texts are constitutive of each other through intertwining loops of revision (Lee 2015, 161). Hsia Yü's work remains within the scope of contemporary "Chinese" poetry even when creating unreadable Chinese-language poems out of English ones, while Ouyang Yu successfully crosses the neat demarcation line (or rather constantly moves to and fro, crossing it once in a while) between Chinese- and English-language literature.

Ouyang Yu uses several strategies for constructing his multicultural identity through his poetic texts. He mixes languages within the space of a single poem, indulges in wordplay, puns, and the creation of new words, maintaining an illusion that it is the reader and not the author who is, in fact, an alien in need of the poet to guide him through the unfamiliar linguistic landscape. Simultaneously, he enjoys using allusions, citations, and twists on tradition that root him in the collective memory of the nation - thus creating an impression of being at home in both cultural pools. This presents an actual and accurate model of this bilingual Chinese author who constructs an identity closely tied to, but at the same time distanced from, the languages he uses.

\section{Works cited}

Chow, Rey. Modern Chinese Literary and Cultural Studies in the Age of Theory: Reimagining a Field. Durham and London: Duke University Press, 2000.

Farrell, Michael. “Poet Ouyang Yu Takes Both Roads.” The Australian 23 February 2013. http:// www.theaustralian.com.au/arts/review/poet-ouyang-yu-takes-both-roads/storyfn9n8gph-1226583520277 (7 February 2015).

Lee, Tong-King. Experimental Chinese Literature: Translation, Technology, Poetics. Leiden: Brill, 2015.

Li, Dian. "Naming and Antinaming: Poetic Debate in Contemporary China." New Perspectives on Contemporary Chinese Poetry. Ed. Christopher Lupke. New York: Palgrave Macmillan, 2008. 185-201.

Liu, Lydia. Translingual Practice: Literature, National Culture, and Translated Modernity - China, 1900-1937. Stanford: Stanford University Press, 1995.

Mair, Victor Henry. "What Is a Chinese 'Dialect/Topolect'? Reflections on Some Key Sino-English Linguistic terms." Sino-Platonic Papers 29 (1991): 1-31.

Nicholl, Jal. “Jal Nicholl Reviews Ouyang Yu.” Cordite Poetry Review 23 February 2013. http:// cordite.org.au/reviews/jal-nicholl-reviews-ouyang-yu/ (7 February 2015).

Ommundsen, Wenche. "Not for the Faint-Hearted: Ouyang Yu, The Angry Chinese Poet." Meanjin 57.3 (1998): 595-609.

Ouyang, Yu. “An Identity CV." Poetry International Rotterdam. 2004. http://www.poetryinter nationalweb.net/pi/site/poem/item/817 (12 February 2015).

Ouyang, Yu. Moon Over Melbourne and Other Poems. Exeter: Shearsman Books, 2005. 
Ouyang, Yu. "Multicultural Poetry as Unwritten in China, or The Night You Want to Sleep Away With or On." Bias: Offensively Chinese/Australian: A Collection of Essays on China and Australia. By Ouyang. Kingsbury: Otherland, 2007. 25-32.

Ouyang, Yu. "About Ouyang Yu." 2010a. http://www.ouyangyu.com.au/ (7 February 2015).

Ouyang, Yu. "Di 皮lation.” White and Yu. 2010b. http://www.presspress.com.au/yu.html (12 February 2015).

Ouyang, Yu. Self Translation. Melbourne: Transit Lounge, 2013. Kindle edition.

Tranter, John, and Webby, Elizabeth. “Ouyang Yu.” Australian Poetry Library. 2004. http://www. poetrylibrary.edu.au/poets/ouyang-yu (7 February 2015).

Tu’ao 凸凹. “Sposob sborki: Interv'yu s Tuao” [Assembly Method: An Interview with Tu’ao]. stikho (t)vor'e [VerseVagrant]. 25 December 2015. https://versevagrant.com/2015/12/25/\%D1\% 81\%D0\%BF\%D0\%BE\%D1\%81\%D0\%BE\%D0\%B1-\%D1\%81\%D0\%B1\%D0\%BE\%D1\%80\% D0\%BA\%D0\%B8-\%D0\%B8\%D0\%BD\%D1\%82\%D0\%B5\%D1\%80\%D0\%B2\%D1\%8C\%D1\% $8 \mathrm{E}-\% \mathrm{D} 1 \% 81-\% \mathrm{D} 1 \% 82 \% \mathrm{D} 1 \% 83 \% \mathrm{D0} \% \mathrm{~B} 0 \% \mathrm{D} 0 \% \mathrm{BE} /(22$ January 2018).

Van Crevel, Maghiel. Chinese Poetry in Times of Mind, Mayhem and Money. Leiden: Brill, 2008. Wang, Jiaxin 王家新. “Preobrazuyushchaya sila yazyka: Interv’yu s Van Tszyasinem” [The Transforming Force of Language: An Interview with Wang Jiaxin]. stikho(t)vor'e [VerseVagrant]. 5 February 2016. https://versevagrant.com/2016/02/05/\%D0\%BF\%D1\%80\%D0\%B5\%D0\% BE\%D0\%B1\%D1\%80\%D0\%B0\%D0\%B7\%D1\%83\%D1\%8E\%D1\%89\%D0\%B0\%D1\%8F-\% D1\%81\%D0\%B8\%D0\%BB\%D0\%B0-\%D1\%8F\%D0\%B7\%D1\%8B\%D0\%BA\%D0\%B0-\%D0\% B8\%D0\%BD\%D1\%82\%D0\%B5\%D1\%80\%D0\%B2\%D1\%8C\%D1\%8E-\%D1\%81-\%D0\%B2/ (22 January 2018).

Yeh, Michelle. “'There Are no Camels in the Koran': What is Modern about Modern Chinese Poetry?" New Perspectives on Contemporary Chinese Poetry. Ed. Christopher Lupke. New York: Palgrave Macmillan, 2008. 9-26.

Yulia Dreyzis is currently an associate professor in the Chinese Philology Department, Institute for Asian and African Studies (IAAS), Moscow State University (MSU), and a researcher at the Institute of Linguistics of the Russian Academy of Sciences. Since 2015, she has managed Russia's only website introducing Chinese contemporary poetry to the Russian-language reader (https://versevagrant.com/). 
